\title{
ESTEREOTIPOS DEL AMOR. SUPERFICIES DE PLACER RUPTURAS EN LAS PORTADAS DE DISCOS DE LOS 70 Y 80
}

\author{
LOVE STEREOTYPES. SURFACES OF PLEASURE \\ RUPTURES IN THE ALBUM COVERS OF THE 705 AND 805
}

\author{
Patricia Medina / patriciamedinatillous@gmail.com \\ Facultad de Artes. Universidad Nacional de La Plata. Argentina
}

Recibido 7/1/2020 | Aceptado 15/4/2020

\section{RESUMEN}

A partir de un repertorio de imágenes de portadas de discos de los setenta y los ochenta, se pretende indagar en diversas modalidades de estrategias comerciales utilizadas por la industria cultural. Modos de circulación y de proliferación masiva de imágenes constituyen un imaginario colectivo que instala determinados prejuicios y valoraciones que se convierten en la moral de las sociedades de consumo. Se analizarán imágenes estereotipadas evidenciando rasgos formales repetitivos que conllevan una fuerte carga ideológica y contribuyen a los intereses de venta. Asimismo, distinguiremos una amplia producción solapada que proponen desde sus supuestas desobediencias nuevas formas visuales. Preguntas asociadas a la construcción de género y a las relaciones sexo afectivas son algunas de las líneas interpretativas que surgirán de estas propuestas. La idea es hacerlas evidentes nuevamente.

\section{PALABRAS CLAVE}

Estereotipos visuales; industria cultural; portadas de disco; new wave

\section{ABSTRACT}

The aim of this work is to look into the different commercial strategies used by the cultural industry based on a choice of images of album covers of the $70 \mathrm{~s}$ and $80 \mathrm{~s}$. Modes of mass circulation and proliferation of images constitute a social imaginary which settles prejudices and valuation turning into the morals of the consumer society. Stereotyped images will be analyzed evidencing repetitive formal features that carry a considerable ideological baggage which contribute to the sales interests. An underhanded large production that new visual forms propose from their apparent disobedience will also be distinguished. Inquiries associated to gender construction and affective-sexual relations are some of the interpretative lines that will arise from this proposal. We want to make them evident once again.

\section{KEYWORDS}

Visual stereotypes; cultural industry; album covers; new wave 


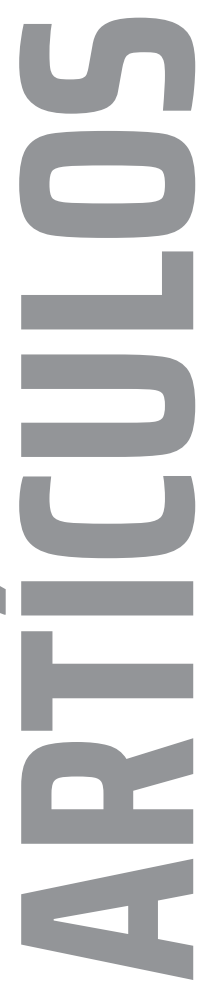

«Ya vi esa imagen, ¿pero dónde?, ¿cuándo?» De pronto recordé: «iEn mi casa de la infancia!, la de la diagonal, en las tapas de cassette de música romántica, por el año 1985». Mi padre tenía la manía de comprar todos los compilados que salían de este género en la disquería de la esquina. Títulos, como Románticos Volumen I, Románticos Volumen II, Románticos Volumen III, Música para enamorarse Volumen IV, Música para enamorarse Volumen $V$ desfilaban por la biblioteca del escritorio que era una especie de almacén de cajitas.

Los recuerdos pueden surgir bajo distintas condiciones. Son incalculables las situaciones cotidianas en las que, por algún encuentro circunstancial, rememoramos acontecimientos o sensaciones del pasado. En relación con esto, resultará interesante dilucidar teorías acerca de aquellos objetos o imágenes que, en nuestro entorno diario, se convierten en los causantes de hacernos rememorar experiencias vividas. Aquí nos detendremos en el aspecto interpretativo y en el sentido otorgado a aquellas formas visuales que se materializan en soportes frecuentes tales como la portada de la tapa de un disco.

Al indagar en las características de las portadas de discos de música romántica de los ochenta, el primer dato a destacar tiene que ver con el hecho de que abundan iconografías en las cuales el tema representado es el amor [Figura 1]. En un sentido muy general, se configura una suerte de género. Sin embargo, la temática común -que implica la repetición de algunas características estructurales- no debería entenderse como un condicionante a la hora de pensar recursos y formas visuales en lo que a sus modos de representación se refiere.

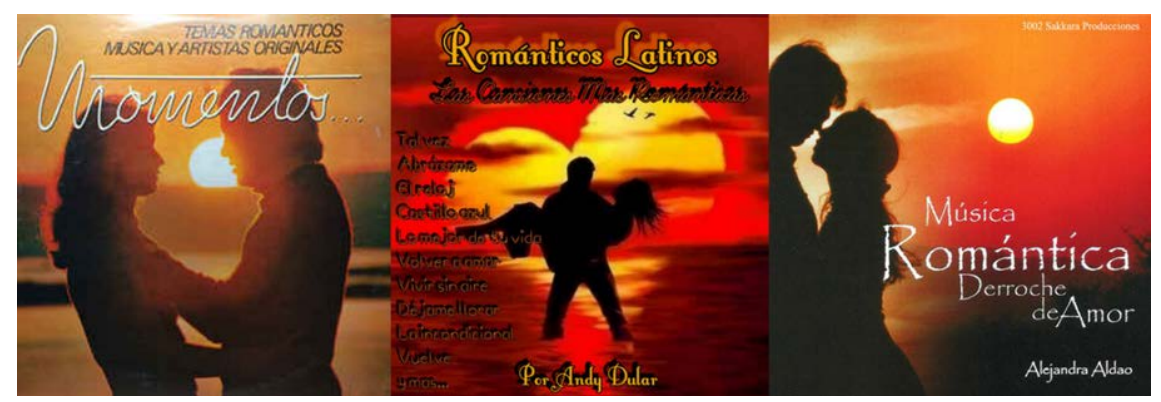

Figura 1. Tapas de discos de música romántica

En sus componentes formales, estas obras se destacan por presentar contundentes similitudes de encuadre y armonías cromáticas. Las escenas comparten un contexto: la playa. Podría ser la de Acapulco. Todos los elementos de la imagen sugieren un momento de absoluta plenitud. Las siluetas de los personajes, ausentes en su identidad, aparecen impostadas en un encuadre tradicional que refuerza el modelo. Un hombre y una mujer, delgados, esbeltos, encuentran sus miradas 


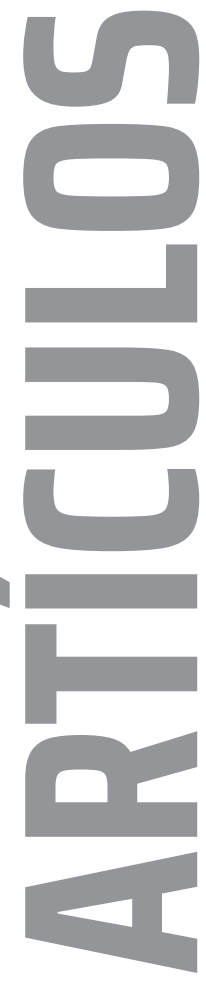

en una arena silenciosa. Cae el sol y tiñe los cielos en donde el mar, de colores cálidos anaranjados y rojizos, descansa en el ocaso. El horizonte frontal, distante, y el contraluz lumínico refuerzan la comunión. El contacto entre ellos es insinuante o bien, cuando se sobrepasa la sugestión, él la eleva en sus brazos triunfales.

Una descripción formal de esas imágenes permite especular que sus elementos constitutivos han sido seleccionados con una intención clara. El protagonismo atribuido, por ejemplo, al contexto de la playa —el cual a su vez se asocia al esparcimiento, al ocio y al placer- refuerza un imaginario colectivo que magnifica las supuestas cualidades idílicas del concepto del amor. En su texto «Los estereotipos en el arte. Un problema de la educación artística. Los artistas son de Piscis» (2008), Mariel Ciafardo y Daniel Belinche describen los estereotipos visuales y destacan, por un lado, la repetición de la imagen por medio de soportes de difusión masiva - pensemos en la televisión, el cine, la música-y, por el otro, la representación de un mismo tema sin transformaciones o alteraciones formales en su composición. ${ }^{1}$ En este caso, en pos de incrementar las ventas del producto, la industria musical construyó hábilmente un repertorio visual preestablecido que encontró en las tapas de discos un soporte accesible y circulable en los entornos familiares. Hasta la llegada de internet y sus plataformas musicales, los discos eran objetos cotidianos en los hogares por lo cual las imágenes de las portadas funcionaban como una herramienta eficaz para instalar determinados códigos sociales.

En Guía ideológica para pervertidos (Fiennes, 2012), documental protagonizado por el filósofo esloveno Slavoj Zizek, encontramos una crítica reflexiva de los profundos trasfondos ideológicos que se esconden en todo estereotipo visual. Se trata de configuraciones generadas y controladas por el mercado. Basta con ver la escena de la película They Live (1988), de John Carpenter, citada en el documental, en la que el protagonista John Nada encuentra una caja repleta de gafas de sol que, al colocárselas, le permiten ver el verdadero mensaje oculto que hay detrás de las imágenes publicitarias.

En vínculo con esto, las tapas de discos de música romántica contribuyen a la construcción de un ideal respecto de lo que se espera de toda relación amorosa. Intentemos describir, a partir de algunas ironías, ciertas situaciones veladas: Ilega el casamiento. También llegan los niños y con los niños por primera vez la decisión de visitar el hipermercado. Un nuevo carrito. El más grande. En el supermercado todo lo necesario está al alcance de la mano. Carnes, lácteos, verduras, gaseosas, snacks, herramientas, toallas, electrodomésticos, pañales, hasta comida para

1 Mariel Ciafardo es titular de Lenguaje Visual 1 y 2 B en la Facultad de Artes (FDA) de la Universidad Nacional de La Plata (UNLP). Daniel Belinche es el actual decano de la FDA. 
el perro. Con las necesidades satisfechas, llega la seguridad. También los viajes familiares y la certeza de saber que, vaya donde se vaya, habrá un Carrefour cerca. Todas las demandas estarán cubiertas.

La infrecuencia de otras posibles formas de representación instala una pregunta. ¿Quiénes diseñan las matrices de estos discursos repetidos?; ¿qué valores, qué intenciones se esconden detrás de las planchas?

\section{LOS MEGADIFUSORES DE IDEALES}

Un dato recurrente en algunos de estos compilados de los ochenta es que dentro de la lista que conformaba el repertorio siempre había por lo menos un single perteneciente a la banda sueca ABBA, con canciones como "Hasta Mañana» 0 «The winner takes its all». Las condiciones en las que ABBA saltó a la fama sirven de ejemplo para desentrañar el modo en que un producto de la industria cultural va adquiriendo forma. En 1974, ABBA se presentó por Suecia en el Mega festival Televisivo de la Canción de Eurovisión —-festival anual de transmisión mundialy obtuvo el primer puesto. Este galardón trajo consigo un gran contrato de grabación nada más ni nada menos que con Universal Music Group (UMG), que comenzó a modelar un fenómeno comercial que alcanzó popularidad y ventas masivas.

Rune Sôderquist, diseñador del logotipo acrónimo de ABBA (formado por las primeras letras de los nombres de los integrantes), fue quién dio un shock de queratina a la imagen de los suecos. En su estudio particular no solo diseñó las portadas de toda la discografía de la banda, sino que también fue quién se ocupó de aquel memorable vestuario pop, brillante y folclórico [Figura 2].

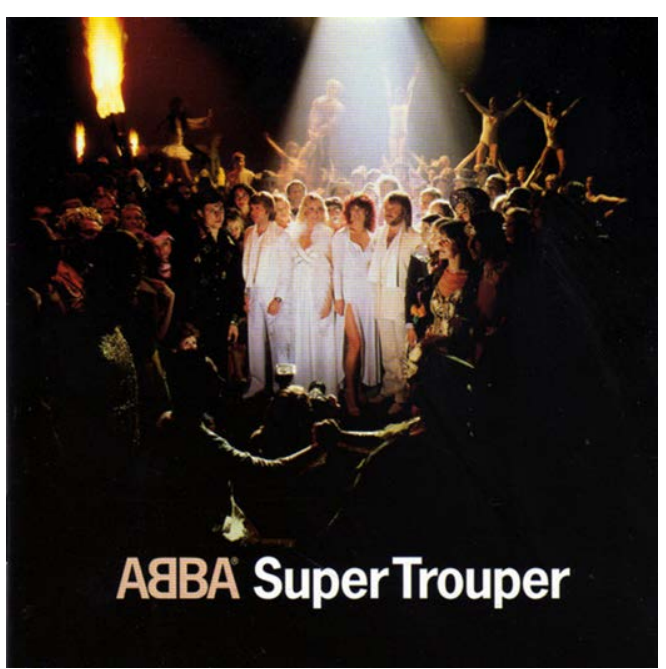

Figura 2. Portada de Super Trouper (1980), de Rune Sôderquist 


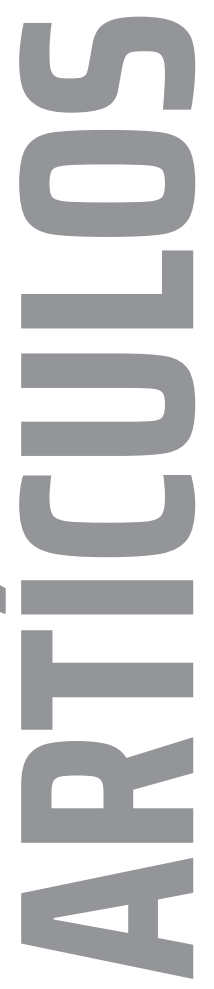

Lo anecdótico es que poco se conoce de los diseños originales de las tapas de la discografía de ABBA. Aquello que ingresaba en las disquerías -más aún en los países latinoamericanos - se ceñía a los nuevos singles, de los cuales también se grabaron unas cuantas versiones en español. Este formato caracterizó la modalidad del grupo sueco y de las discográficas contratantes, por lo que las espectacularizaciones ficcionales de Sôderquist quedaron relegadas a los albores de la historia del diseño de tapas de discos. Las tapas triunfantes reproducen los clásicos retratos fotográficos en donde el único dato a relevar es el aspecto fisionómico de los personajes del grupo [Figura 3].2

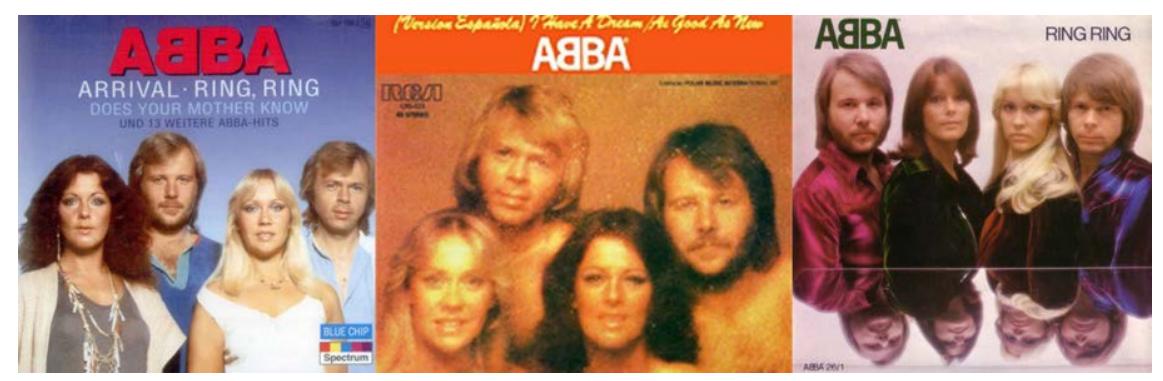

Figura 3. Portadas de discos compilados de ABBA

El tipo de encuadre es simétrico, reiterativo. Centrado, congruente, estable. Prolijo. Afable. Los fondos, despojados de cualquier posible espacio, neutros. Los integrantes posan dócilmente ante la cámara. El resultado es una neutralidad vacía de sentido visual. La singularidad de crear una subjetividad en los personajes retratados a partir de escenografías elaboradas — aspectos que son la esencialidad poética de Sôderquist- está ausente.

La elección del dispositivo fotográfico, que «por su uso y su lectura se fueron convirtiendo en algo habitual» (Berger, 1998, p. 48), adquirió la característica del «modo dominante y más natural de remitirse a las apariencias» (Berger, 1998, p. 47). Esta posibilidad de la fotografía evidencia el motivo por el cual la industria musical se valió del retrato tradicional como la técnica y el modo de representación predominante que permitirá adaptar la imagen a una amplia variedad de tamaños y soportes. La idea del «método transparente más directo de acceso a lo real» (Berger, 1998, p. 47) es acentuada por la curiosidad de la audiencia.

El cuarteto sueco expresó la clara división entre lo masculino y lo femenino. El orden estructural compositivo instaló una partición simétrica del encuadre. Las dualidades distinguidas. La imagen se redujo a la presentación de los

2 El pop sueco extendió su fórmula de la pareja heterosexual rubia y anglosajona con bandas como Roxette o Ace of Base. 


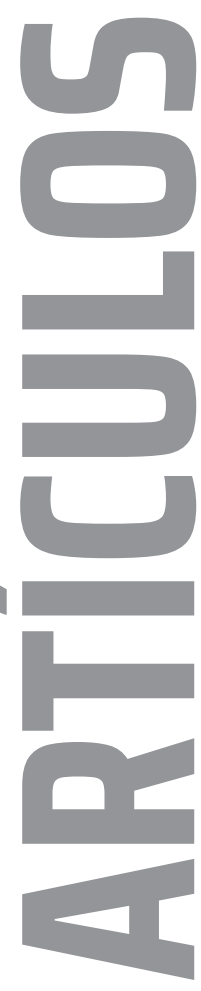

integrantes. Un dato: ambas duplas conformaban matrimonios entre sí, con lo que no solo los unían sus canciones y contratos sino también su condición civil.

Hasta aquí, podemos aseverar que, tanto en las tapas de disco de música romántica como en las tapas de disco de ABBA, las parejas constituyentes - entendiendo a este elemento como estructural del género- son representadas teniendo en consideración dos cuestiones: por un lado, la utilización del modelo binario hombre-mujer y, por el otro, la asignación de cualidades genéricas, a modo de ejemplares modelos. El qué y el cómo de la imagen, en este contexto temático, se concentra significativamente en el elemento visual de las parejas para otorgar determinado sentido a lo representado.

\section{DE DISEÑADORES, CORRIMIENTOS Y ANÉCDOTAS}

Si tomamos ese rasgo formal - la representación de parejas en tapas de discosy lo trasladamos a otros estilos musicales, encontraremos que, en la misma década, circulaban en simultáneo propuestas visuales en donde la representación de la dupla hombre-mujer se veía alterada y transformada, convirtiéndose en la forma poética por excelencia que llegó para cuestionar los discursos hegemónicos evocados por las imágenes anteriores.

Los paradigmas de la filosofía nietzscheana, así como del psicoanálisis freudiano, que reconocen un lugar positivo a la dimensión corporal, afectiva y deseante del sujeto, habilitan la idea de la utilización del cuerpo como material artístico, lo que conlleva a convertirlo en un soporte de símbolos que visualizan, entre otras cuestiones, profundos cambios en las estructuras sociales. Las teorías de Michel Foucault respecto de «las múltiples y sutiles formas de ejercicio del poder», como por ejemplo, «el dispositivo de la sexualidad [...] para disciplinar a las masas» (Citro, 2010, pp. 28-29) se consolidan como el marco conceptual para comprender las nuevas corporalidades contemporáneas, las cuales encuentran en los movimientos contraculturales musicales de las décadas de los setenta y de los ochenta - tales como la new wave, el punk rock y el glam- sus orígenes. Estos estilos se convirtieron en el dispositivo artístico por excelencia para cuestionar las problemáticas del género.

Las rupturas de paradigmas tradicionales - que comenzaron ya por los sesenta, con los hippies al frente- se instalaron en la cotidianidad de los jóvenes de los setenta, quienes encontraron en la interpretación y la manifestación corporal la materialidad esencial para resaltar y sostener nuevos ideales. Evitaremos, por cuestiones inherentes a la concesión temática, analizar si estas tendencias rupturistas en lo estético tuvieron su correlato político. 


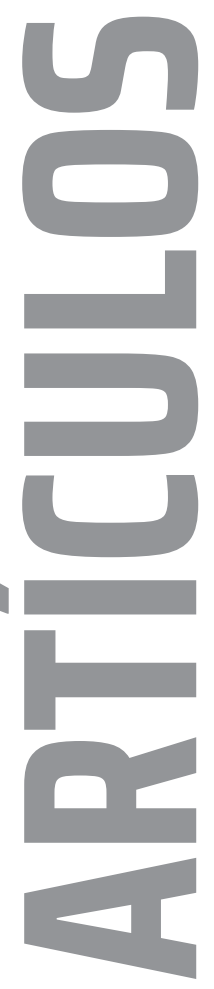

El retrato fotográfico continuó siendo una herramienta clave para fijar las apariencias concretas del personaje de rock. Asimismo, las puestas en escena combinadas con técnicas teatrales, la importancia de la imaginería transmitida por la escenografía y las extravagancias en las vestimentas construyeron un conjunto de asociaciones que caracterizaron a los nuevos movimientos. Dentro de esta pequeña categoría, David Bowie fue uno de los primeros en presentar una estética visual repleta de interrogantes con respecto a las matrices instaladas en torno al género.

En Pin Ups (1973), retrato de Justin de Villenueve [Figura 4], la imagen presenta una relación de figura y fondo contrastante. El color cian, con sus propiedades luminosas y estridentes, cumple la función de telón futurista. Su misión es destacar el efecto de extrañamiento de los protagonistas. La dupla hombre-mujer no termina de resolverse con claridad. La robustez esperable en el cuerpo masculino y la voluptuosidad curvilínea en el cuerpo femenino se encuentran sustituidas por cualidades tales como la delgadez y la delicadeza de ambos cuerpos. El tamaño de plano medio colabora con esta confusión al jugar con un desencuadre que deja por fuera la posibilidad de ver el busto de los personajes. Los peinados también invierten sus roles complejizando aún más la interpretación y el maquillaje idéntico en ambos rostros refuerza lo paradojal. No hay vestimenta, no hay atributos, solo cuerpos en los que la calidad del tono de las pieles, no terminan de completar una idea concreta. El bronceado prominente de uno de los personajes, únicamente en cuello y torso, contrasta con la claridad absoluta de su propio rostro y del cuerpo del acompañante, como si vida y muerte convivieran en un mismo tiempo y espacio. El resultado es una imagen ambigua, andrógina, desprovista de certezas respecto del género.

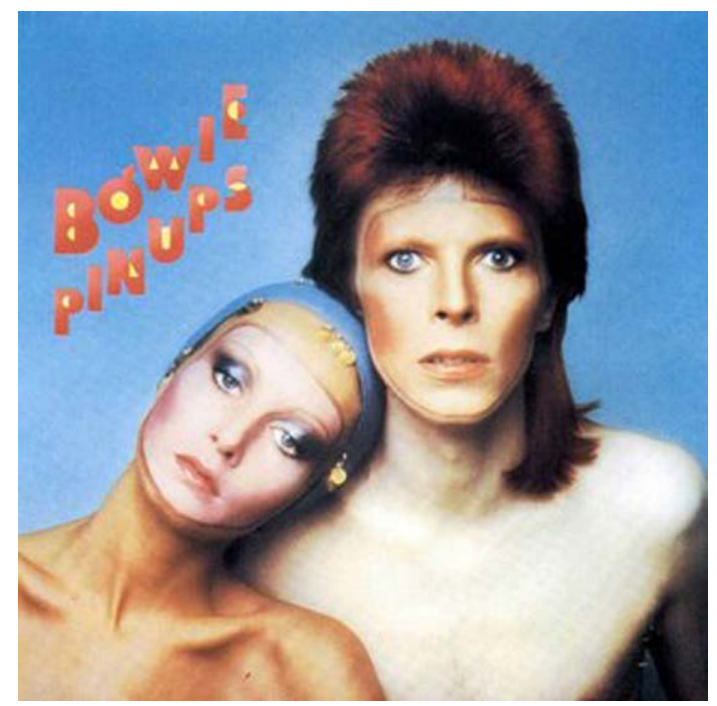

Figura 4. Portada de Pin Ups (1973), de Justin de Villenueve 
Una anécdota narrada por el mismo De Villeneuve -en los albores de los setentase refiere a un encuentro con Bowie en una fiesta donde este le manifiesta su presunción de convertirse en el primer hombre en ser retratado para la portada de la revista Vogue. De Villeneuve, quién no solo se destacó por ser un reportero gráfico de renombre, sino que fue marido y luego mánager de Leslie Lawson —-más conocida como Twiggy—, no dudó en proponerle realizar una sesión de fotos para tal fin. Recordemos que Twiggy, a partir de su carrera como modelo publicitaria, asentó un nuevo ideal de belleza en el cual la delgadez, las líneas estiradas y los cabellos cortos pasaron a conformar los rasgos esenciales de los cuerpos femeninos. Fue así como al volver de unas vacaciones en las playas caribeñas, se presentó con su espléndido bronceado para acompañar a Bowie en las sesiones fotográficas. Dichas fotografías fueron rechazadas por la revista, pero esa decisión corporativa habilitó su resignificación y dio lugar a una de las portadas de disco más conocidas de la historia del glam rock.

Otro ejemplo pertinente de análisis con relación a las duplas es la tapa del disco New York Dolls (1973) [Figura 5] del conjunto musical estadounidense homónimo, que presentaba sus shows en la sala Oscar Wilde, del Mercer Art Center de Nueva York, en los comienzos de los setenta. Una propuesta caracterizada por sus excesos visuales y sus transformismos en escena.

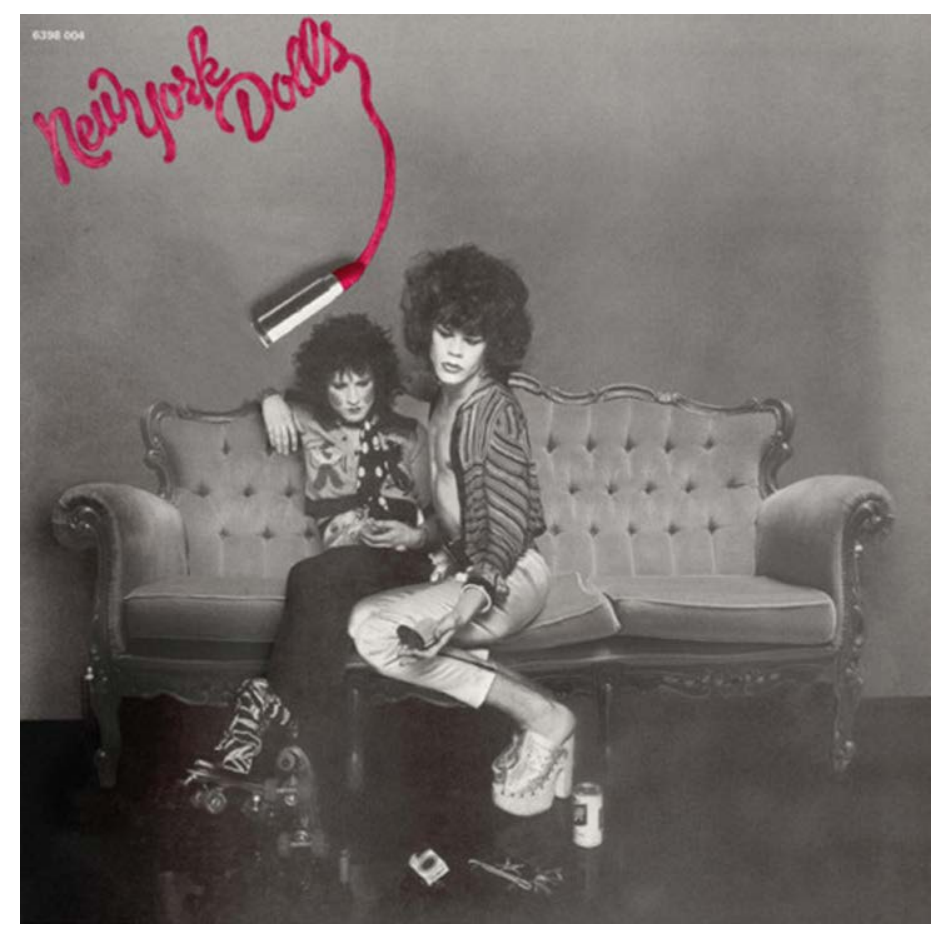

Figura 5. Portada de New York Dolls (1973), de Bob Gruen 


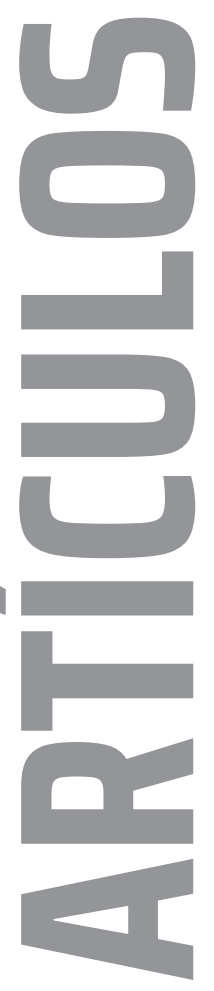

El encuadre es tradicional, explícito. La pareja protagonista posa sentada en un sillón de estilo victoriano que evoca un contexto romántico y opulento. El personaje principal se destaca del segundo por su ubicación perfectamente centrada en el campo plástico. La iluminación y el maquillaje enfatizado en su rostro y la postura erguida, sensual y sugestiva del personaje imponen aún más su presencia. El peinado elaborado a partir del brushing y el fijado del volumen acentúa su porte de señora acaudalada. La exageración del calzado en la elección de las plataformas y las vestimentas ajustadas distorsionan el sentido hacia los estereotipos visuales de la prostitución y lo grotesco. Los brillos destacados en las calidades de las superficies de las telas de la vestimenta evocan poliéster barato que imita al satén o al lamé. El personaje secundario aparece como un alter ego caricaturesco del primero. Los atributos analizados se presentan de manera ridícula y bufa. Toda la imagen resulta exacerbada, extravagante. La incongruencia se intensifica con el lápiz labial rojo como único aspecto cromático, también magnificado en sus proporciones de escala y utilizado para transcribir la frase «Muñecas de Nueva York», una referencia que es sustituida visualmente por la presencia de señoronas travestidas de la baja alcurnia.

Este trabajo artístico de Bob Gruen, sumado a su infinidad de retratos a músicos de la época, ha contribuido a la generación de la imagen de estrella de punk/rock que aún hoy la industria musical se encarga de hacer circular en una amplia variedad de soportes como remeras, llaveros y pósteres.

Una última portada pertenece al fotógrafo y diseñador Rob o'Connor —-fundador del estudio de diseño gráfico Stylorouge-, quien supo capturar el instante preciso de la escena erótica protagonizada por el dúo británico Siouxsie Sioux y Budgie [Figura 6].

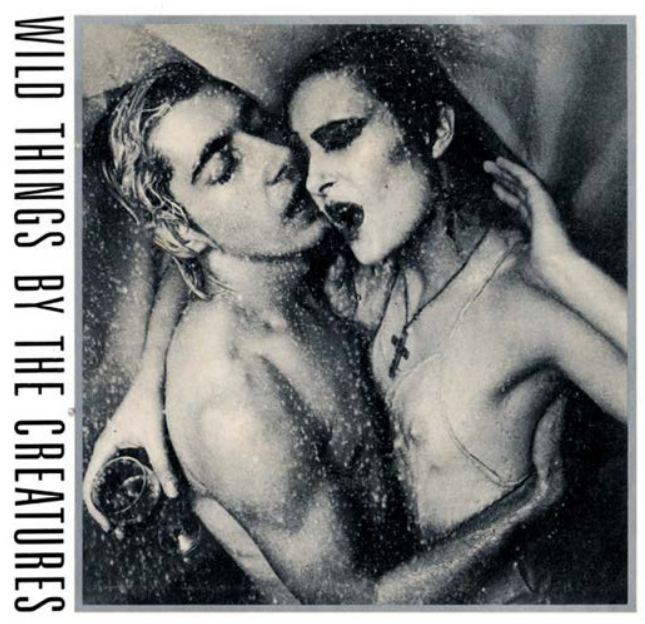

Figura 6. Portada de Wild Things (1981), de Rob O' Connor 


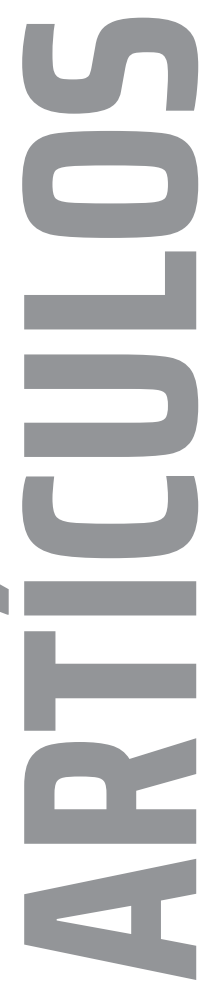

El diseño de tapa corresponde al primer EP de The Creatures (integrantes a su vez del grupo musical inglés Siouxsie and the Banshees) quienes presentan a partir del título Wild Things (1981) una propuesta que destaca el aspecto sexual por sobre otras cualidades que la temática del amor pudiera evocar. Los personajes ocupan la totalidad del campo plástico. El tamaño de plano corto colabora con la sensación de cercanía del espectador respecto de los retratados. El exhibicionismo se pronuncia a partir de la desnudez de ambos cuerpos, lo que es enfatizado por los destellos lumínicos provocados por el agua derramada sobre estos. El contexto del baño y la ducha — sugerido por la cortina de fondo- refuerza el momento privado e íntimo, dejando al espectador expuesto a una situación de voyerista. El atributo del crucifijo se percibe incoherente, la desobediencia del cuerpo excitado contra la voluntad de la tradición cristiana. El instante congelado del placer es reforzado por el nombre del disco y de la banda. Las criaturas inspiradas por un instinto salvaje intensifican la añeja separación entre el cuerpo y las ideas, entre el instinto y la razón, entre la libido y la voluntad. La copa de vino desinhibe las pulsiones. Los cuerpos comienzan a desobedecer y se perciben sus transformaciones en el individuo urbano.

\section{OTRAS IMÁGENES PAGANAS}

Aquí, en la Argentina, los comienzos visibles de estos nuevos movimientos musicales surgieron de la mano de Virus, la banda platense de principios de los ochenta liderada por los hermanos Moura. Sus looks, que combinaban vestimentas, peinados y sonidos electrónicos característicos de la new wave, encontraron en la figura predominante de Federico Moura — cantante y líder de la banda-, una personalidad artística destacable cuya imagen corporal se convirtió en una insignia crítica a los modos masculinos convencionales [Figura 7].

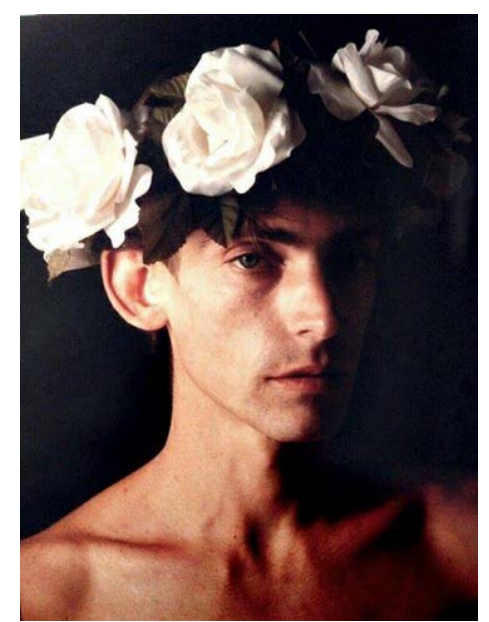

Figura 7. Retrato de Federico Moura (s. f.), de Eduardo Martí 
Superficies de Placer (1987) fue el cuarto disco de Virus y el tercero ilustrado por Daniel Melgarejo [Figura 8], quien fue construyendo una estética acorde a la propuesta provocativa de la banda. A partir de las letras de sus baladas eróticas se hacían alabanzas al valor del acto sexual, al deseo físico y a la masturbación.

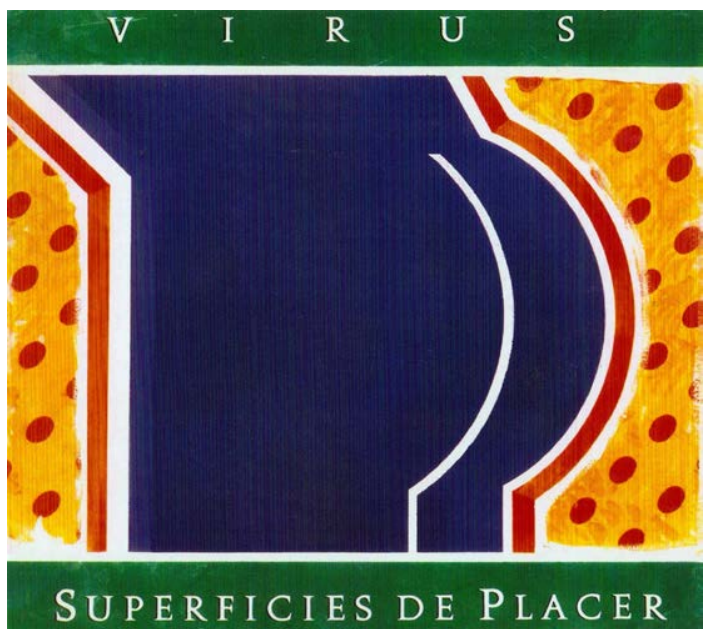

Figura 8. Portada de Superficies de placer (1987), de Daniel Melgarejo

El atardecer o el amanecer de las primeras portadas de música romántica es sustituido aquí por el primerísimo primer plano de un culo - si nos permitimos la vulgaridad-, subrayado con el recurso de una línea homogénea que contornea doblemente la silueta y la destaca de su fondo. La síntesis formal se limita a este único elemento sobre un fondo de texturas lunares festivas. La armonía de colores primarios refuerza esta idea. El anclaje discursivo sugerido por el texto de la gráfica y el título del long play advierte un giro interpretativo a la vez que establece una asociacióny un anclaje contundente. La elección del modo ilustrativo despersonaliza y generaliza, establece una distancia de cualquier posible referente.

Las nalgas de Melgarejo están sustituyéndolo todo. La playa. La pareja elíptica. Lo sexual. La relación bucólica con la naturaleza y la experiencia sublime de la plenitud es representada esta vez por los placeres del cuerpo. Increíblemente distante, en su estructura y en su forma, tal vez esta sea la propuesta más cercana a aquellas sensaciones idílicas evocadas por las parejas acarameladas en las playas del atardecer. El placer eterno representado en el instante presente.

Para finalizar podríamos reflexionar sobre cómo se construyó —al interior del artículo-el puente que une las primeras tapas de discos de música romántica con las propuestas visuales del punk y la new wave. La respuesta se hallará al realizar nuevamente el recorrido por los ejemplos visuales una vez concluida la lectura. 


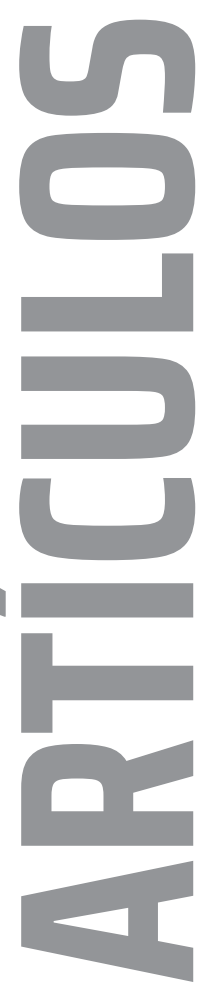

En unextremo, aquellasrecetas compositivasque, en su incesantereproductibilidad, determinan y regulan los comportamientos, las afectividades y las creencias de la sociedad en su conjunto, instalando consideraciones respecto de qué es lo normal y lo natural en los vínculos interpersonales. En la otra orilla, movimientos gestados en los albores de la década de los setenta — reforzados en la continuidad de los ochenta- que proponen, a través de nuevas maneras de representar y de concebir el cuerpo, una cosmogonía de nuevas formas visuales que interpelan de manera soslayada nuestras subjetividades y nuestros modos de ser en el mundo.

Han transcurrido alrededor de cincuenta años de este movimiento en el que músicos, diseñadores, fotógrafos y performers construyeron estas novedosas iconografías -algunas veces transgresoras otras contestatarias, sin duda controversiales para la época - las cuales dieron lugar a la utilización de las corporalidades como material artístico, manifestando las problemáticas del género y convirtiéndose en resistencia de la diversidad.

En la actualidad estas propuestas originarias comienzan a verse amenazadas y corren el riesgo de convertirse ellas mismas en paradigmas del estereotipo del cantante de rock y en producto mercantil de una nueva moda. Como ejemplo de este presagio, Juan Carlos Kreimer escribió el título de su obra Punk, la muerte joven [1978] (2015) como un indicio del intento de las compañías discográficas de oficializar a los nuevos movimientos de aquellos tiempos. Cabe preguntarnos asiduamente sobre el modo de circulación de estas imágenes representativas de los citados estilos musicales, sus medios de difusión y su continuidad en el tiempo. Definitivamente, el espíritu de indagación dependerá de los ánimos del lector.

Queda hoy, como camino a seguir en torno a estos interrogantes, la búsqueda de un equilibrio, de un punto medio en donde lo revolucionario no termine convirtiéndose en un cliché. Como siempre, serán los artistas y sus poéticas quienes quiten las vendas de nuestros ojos al proponernos nuevas maneras de abordar los grandes temas de la humanidad. Confiemos en que sean ellos quienes no deban cantar batalla perdida.

\section{REFERENCIAS}

Berger, J. (1998). Usos de la fotografía en Mirar. Ciudad Autónoma de Buenos Aires, Argentina: Ediciones de la Flor.

Carpenter, J. (Director). (1988). They Live. Estados Unidos: Alive Films.

Ciafardo, M. y Belinche, D. (2008). Los estereotipos en el arte. Un problema de la educación artística. Los artistas son de Piscis. La Puerta. Publicación de Arte y Diseño, 3(3), 27-38. Recuperado de http://papelcosido.fba.unlp.edu.ar/pdf/revistas/lapuerta/ LaPuerta-3.pdf

Citro, S. (2010). Cuerpos plurales. Antropología de y desde los cuerpos. Ciudad Autónoma de Buenos Aires, Argentina: Biblos. 


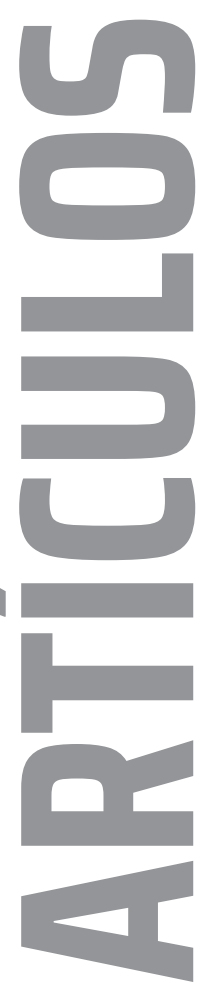

De Villenueve, J. (1973). Pin Ups [Diseño de portada de disco]. Recuperado de https:// www.discogs.com/es/Bowie-Pinups/release/440664

Fiennes, S. (Directora). (2012). Guía ideológica para pervertidos

[Documental]. Recuperado de https://www.youtube.com/ watch?V=CMRM_bfCBig\&list=PLod6sJU7EkzoUKPgzTZBOAC09pkn4OUIZ-

Gruen, B. (1973). New York Dolls [Diseño de portada de disco]. Recuperado de https:// www.discogs.com/es/New-York-Dolls-New-York-Dolls/master/13185

Kreimer, J. C. [1978] (2015). Punk. La muerte joven. Ciudad Autónoma de Buenos Aires, Argentina: Planeta.

Martí, E. (año). Retrato de Federico Moura [Fotografía]. Recuperado de https://www. instagram.com/p/BanOnwzBMEW/.

Melgarejo, D. (1987). Superficies de placer [Diseño de portada de disco]. Recuperado de https://www.discogs.com/es/Virus-Superficies-De-Placer/release/7038678

O' Connor, R. (1981). Wild Things [Diseño de portada de disco]. Recuperado de https:// www.discogs.com/es/The-Creatures-Wild-Things/release/496429

Sôderquist, R. (1980). Super Trouper [Diseño de portada de disco]. Recuperado de https://www.discogs.com/es/ABBA-Super-Trouper/release/1431832 